\title{
TRACE ANALYSIS BY LASER-EXCITED ATOMIC FLUORESCENCE WITH ATOMIZATION IN A PULSED PLASMA
}

\author{
O.S. LUNYOV, S.V. OSHEMKOV and A.A. PETROV \\ Institute of Physics, Leningrad State University, Ul'Yanovskaya 1, Petrodvorets, \\ Leningrad 198904, USSR
}

\begin{abstract}
The posgibilities of plasma atomization for laser flucrescence trace analysis are discussed. Pulsed hot hollow cathode discharge was used for analysis of solutions and powdered samples. The high voltage spark and laser-Induced breakdown (laser spark) were used as atamizers of metal-containing atmospheric aerosols. Detection limits were inoroved by means of temporal beckgraind selection.
\end{abstract}

\section{INTRODUCTION}

Plasma is widely used in spectrochemical emission analysis. Both sarrele evaporation and excitation of spectra of atoms under determination are carried out in plasma. Today ICP-Ahs is one of the most universal analytical techniques in the world. Glow discharge enission method (GD-AES) is widely used for the analysis of dry residues of solutions, powders and solid samples (1-s). Fri GD succesfully deals with non-conducting sample analysis. The laser-induced breakdown spectroscopy (LIBS) is also perspective for the aerosols-containing gases monitoring $(4,5)$.

However the production of high-pure substances today needs the higher sensitivity than 0.01-1 ppm level usually obtained by emission analysis. One of the ways to improve the analytical performance of the methods based on plasma atamization is to use the laser-excited atamio fluorescence. It is well known that in some cases the single atom can be detected by this technique $(8-8)$. Besides the pulsed plasma atomization is more suitable for the pulsed lasers usually used in laser fluorescence than the continuous atomization. Moreover, the pulsed plasma makes it possible to pump atoms from the excited or metastable levels for the element that could not be excited by laser radiation from the ground state directly ( 9 ).

The article demonstrates the analytical possibilities of laser fluorescence with pulsed plasma atomization in the case of trace analysis of solutions, powders and aerosols.

\section{PULSED HOT HOLLON CATODE DISCHAFGE}

\subsection{Instrumentation and operating paramotars.}

In the present experiments, the quartz water-cooled discharge tube (Fig.1) was used. The discharge elrcuit included stabilized high voltage d.c. power supply (up to $2 \mathrm{kV}$, up to $1.5 \mathrm{~A}$ ) and $500 \mathrm{Ohm}$ ballast resistor. The possibility was provided for pulsed operation of the hollow cathode discharge. The liquid or powdered sample was placed at the botton of the cathode. The atomization process took place under the cathode temperature up to $1800^{\circ} \mathrm{C}$ (cathode current 
$0.6-0.8 \mathrm{~A}$ after a minute"s ashing at $1000^{\circ} \mathrm{C}$ (about $0.3 \mathrm{~A}$ ).

The fluorescence was excited by a pulsed dye laser, pumped by YAG:Nd3+ laser. The spectral width of the second harmonic dye laser radiation was $0.03 \mathrm{~nm}$, palse duration $10 \mathrm{ng}$, pulse energy up to $0.02 \mathrm{~mJ}$ and the repet1tion rate $12.5 \mathrm{~Hz}$. The laser bean has rectangular cross-section $\left(3.2 \mathrm{~mm}^{2}\right)$. The lower edge of the bean was about $3 \mathrm{~mm}$ above the higher edge of the hollow cathode. The fluorescence radiation was collected from the zone above the hollow cathode cavity and focused through callbrated attenustors onto the entrance slit of the monochromator. For spectral filtering of the fluorescence radiation an Cherny-Turner type monochranator (2 nm/ $\mathrm{mm}$ ), equiped with a ruled grating (1200 groves $\mathrm{mm}^{-1}$ ) was used. The electric sigmal from the EMT was measured and converted into digital data by a boxcar integrator with time resolution of $4 \mathrm{~ns}$.

For the determination of $\mathrm{Co}$, Stokes direct line fluorescence mesured at $340.512 \mathrm{~nm}$, after excitation at $304.400 \mathrm{~nm}$. In the case of $\mathrm{N1}$, the fluorescence excited at welength $301.914 \mathrm{~nm}$ and was detected at $310.155 \mathrm{~nm}$. In both cases the spectral slit width of monochromator was $0.2 \mathrm{~nm}$. The spectral power density of the exciting laser radiation was sufficient to saturate the selected transitions.

\subsection{Results and discussion}

The process of sample atomization at different hollow cathode temperatures, dependence of signal on pressure and sort of a discharge gas were investigated with the aim of choosing the optimum experemental conditions for the analysis.

Effect of cathode temperature on the fluorescence intensity is 11lustrated by Fig.2. It shows that signal increeses with rising of the cathode tenperature. However, the increase in the atamizer temperature results in a significant increase the emission radiation from the analytical zone. That is connected with temperature through the discharge current. Thus the main problem in the d.c. hot hollow cathode dischange is to reduce emission beckground.

The time dependence of the fluorescence of cobalt at a fixed hollow catode temperature and for different inert gases is shown in Fig. 3. The sample atonization time decreased when the discharge gas rag changed from He to $\mathrm{Ne}$ and then to Ar. Thus at $1500^{\circ} \mathrm{C}$ the mechanism of atanization is two-fold: besides the thermal atomization a large role is played by cathodic sputtering. This can be easily seen for the heavier gas Ar, when cathodic sputtering is more effective than in the case of $\mathrm{He}$ and $\mathrm{Ne}$.

Effect of cas pressure on intensities of fluorescence and emission beckground is shown in Fig.4. As can

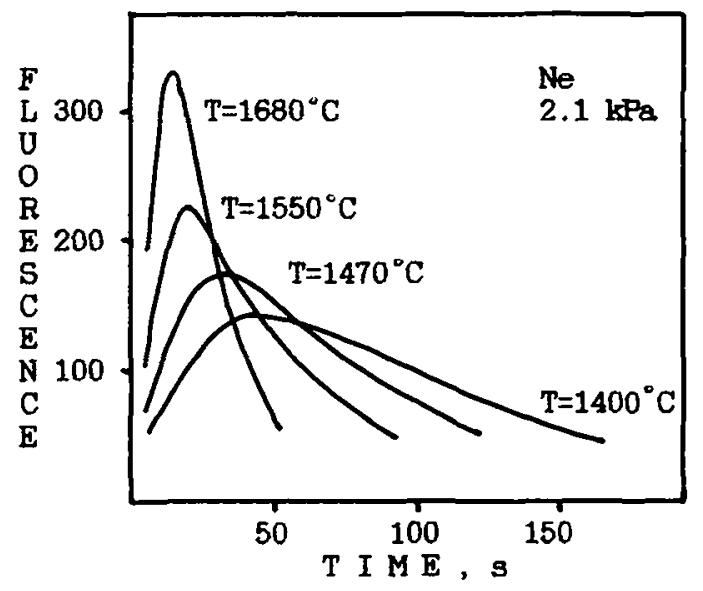

Fig.2. Tenporal behavior of fluorescence at different cathode temperature 
be seen the fluorescence signal increased with increasing of pressure. This is due to the increasing atomic vapour concentration near the cathode cavity resulting from an increase in the diffusion time. Furthermore, the emisgion beckgraund was reduced with the increase of gas pressure becouse the bright enitting plasma was confined into the cavity. Unfortumately, the possibility

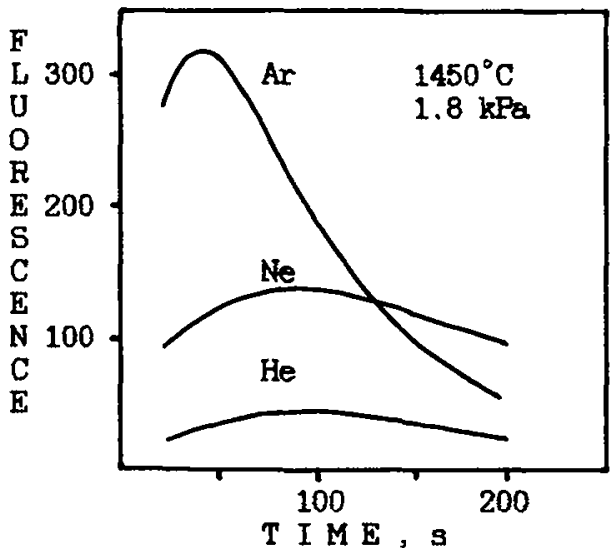

Fig. 3. Fluorescence in different gases

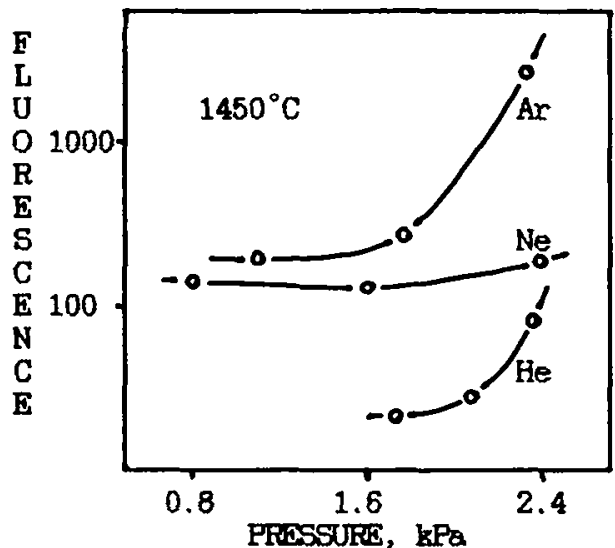

Fig.4. Fluorescence versus pressure

of increasing the gas pressure was linited by the stability region of the hollow cathode discharge. An arc-mode was initlated by further increase in pressure. Therefore the optimm pressure of the discharge gas is near the arc-mode regime of hot hollow cathode discharge. Bowever it was ingosibible to measure low atam concentrations by operating the lamp in the direct current mode, because of the enission background of the hollow cathode plasma.

In order to ingrove the sigmal to beckgrand ratio pulsed operation of the hot hollow cathode was used. Efficient elimination of enission beckground was obtained by periodical switching off the discharge and excitating the fluorescence in the afterglow. This technique rectuced the detection limit by 2 orders of magnitude. The pulsing of the plasma was provided by an electronic circuit synchronized with the laser pulse. It wes fand that the plasma was quickly $(-1 \mu s)$ extinguished after the discharge interruption, while the intensity of fluorescence remained constant for $300 \mu \mathrm{s}$. This is explained by the fact that the atomizer temperature was decreasing slowly and was practically constant at the used pulse curation.

Calibration was obtained on the basis of aqueaus solutions with known Co and $\mathrm{N1}$ content. To obtain the detection limit the curve ras extrapolated to a value equal to three times the standand deviation of the becikgrand, determined by non-selective scattered laser radiation (wide-band luminiscence of ralls and windows of the discharge tube which was caused by laser radiation). Resulting LOD are: $0.02 \mathrm{ppb}$ for Co in dry residues of aqueaus solutions and $5 \mathrm{ppb}$ for $\mathrm{Ni}$ in dry residues of aqueaus solutions. This analytical results are comparable with laser fluorescence - ETA detection limits and better than results obtained by laser fluorescence with other atomization teckniques (see review (10)).

Determination of $\mathrm{CO}_{1}$ in powdered $\mathrm{Al}_{2} \mathrm{O}_{3}$ and $\mathrm{SHO}_{2}$ was carried out with a procecure sinilar to that described above. Detection limits obtained are: 5 ppb for $\mathrm{Co}_{0}$ in $\mathrm{Alz}=3$ and $1 \mathrm{ppb}$ for $\mathrm{Co}_{\mathrm{O}}$ in $\mathrm{SiO}_{2}$. However, optimum analytical conditions proved to be different: for Co determination in aqueous solutions, the gas (Ne) pressure was set at $2.1 \mathrm{kPa}$ and the cathode temperature at $1600^{\circ} \mathrm{C}$, while in the case of powders gas pressure has $1.8 \mathrm{kPa}$ and the cathode temperature $1500^{\circ} \mathrm{C}$. This was caused by the lower stability of the hollow cathode discharge operated with the powdered sample. For better analytical performances the stability should be improved at higher operating values of temperature and pressure. 


\section{SPARK PLASMA}

Another type of pulsed gas discharge was used for the laser-excited fluorescence analysis of metals in air. Atonization of atmospheric eerosols was realised in the laser spark formed by focused radiation of the power laser or in the high-voltage spark discharge with very sinilar energy and time parameters. The main actvantages of method with laser spark are:

- the possibility of analysis in real time without any sampling;

- elimination of electrode' 3 inpurities;

- high temperature that should enable high efficiency of atonization;

- high sensitivity of the analysis.

Farlier Radziemski et al (4,B) used laser-induced breakdown spectroscopy (LIBS technique) for spectrochemical analysis of metals in the air detecting the emission spectra. However in that case laser spark wased both for the sample atomization and excitation of atoms under determination. At the same time sufficient decrease of detection limits can be obtained when a spark discharge in the air is used only for aerosols evaporation, which is then followed by fluorescence detection of atoms under determination. Such an opportunity was shown in the case of analysis of Na-containing aerosols in the air.

\subsection{Instrumentation and gaerating parameters.}

Atomization of Na-containing atmospheric aerosols was carried out in the laser spark induced by focused radiation $\left(10^{11} \mathrm{~W} / \mathrm{cm}^{2}\right.$ power density) of the Q-switch ruby laser (20 ns pulse, up to $0.4 \mathrm{~J} / \mathrm{pulse}, 1 \mathrm{~Hz}$ repetition rate) or in the high-voltage spark discharge (1 nF, $10 \mathrm{kV}$ through the pulsed coaxial transformer 1:4) with very similar time and energy parameters.

Concentration of $\mathrm{Na}$ in the air was created by spraying aqueous solution of $\mathrm{NaCl}$ with $\mathrm{Na}$ content $10 \mu \mathrm{g} / \mathrm{ml}$. The dye laser (5 ns pulse width, $0.15 \mathrm{~mJ} / \mathrm{pulse}$, $0.05 \mathrm{~nm}$ linewidth, up to $50 \mathrm{~Hz}$ repetition rate) was pumped by $\mathrm{Nz}$ laser. To record resulting fluorescence monochromator with $f / 2.5$ aperture, $2 \mathrm{~nm} / \mathrm{m}$ reciprocal linear dispersion and PMT connected with boxcar integrator (4 ns gatewidth, $50 \mathrm{Omm}$ ) were used.

\subsection{Results and discussion}

The sodium atoms fluorescence was pumped by pulsed dye laser radiation with varying time delay respectively to the spark discharge. To reduce the non-selective scattered radiation on the wavelength of registration, various components of $\mathrm{Na}$ yellow duplicate were used for exciting and recording the fluorescence (589.6 $\mathrm{nm}$ and $589.0 \mathrm{~nm}$ respectively). The analytical level $32 \mathrm{P}_{3 / 2}$ has populated from the level $32 \mathrm{P}_{1 / 2}$ ( $\triangle E=0.002 \mathrm{eV}$ ) through collisional processes in the air.

The laser spark discharge had a continuous spectrum and relaxed during about $0.5 \mu \mathrm{s}$ after the breakdown (Fig.5). Plasma emission of the high-voltage spark in the air had the same kinetics. At the presence of $\mathrm{Na}$-containing aerosols in the analytical zone emission of $\mathrm{Na}$ atams excited in the spark superimposed on the spark own glow and exceeded it in duration. Radziemski et al (4) used the differences in kinetics of plasm backerround and emission signal of atoms determined for decreasing of detection limit. Other possibility to reduce enission background is to excite the fluorescence in the afterglow of spark discharge. The experiment shows (Fig.6) that the maximum

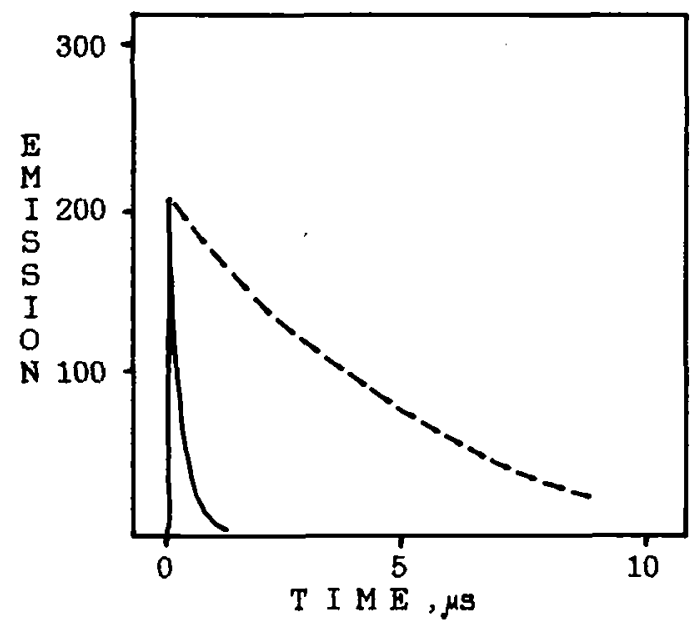

Fig.5. Kinetics of spark plasma ( - - Na presence in the air) 


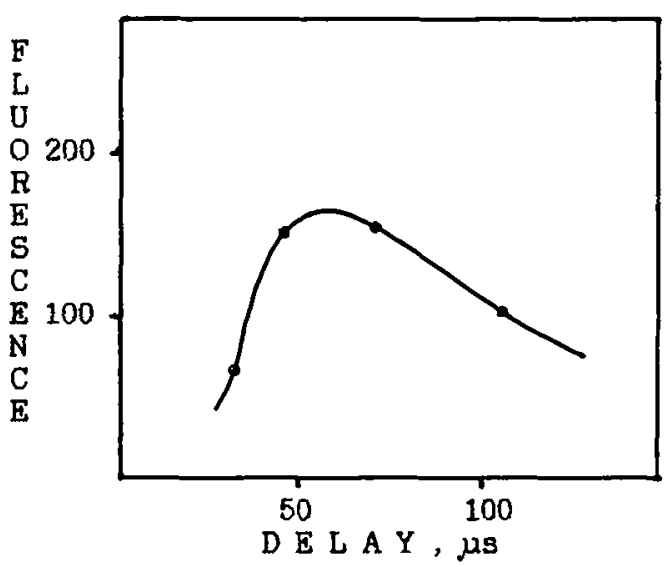

Fig.6. Na fluorescence as a function of delay time

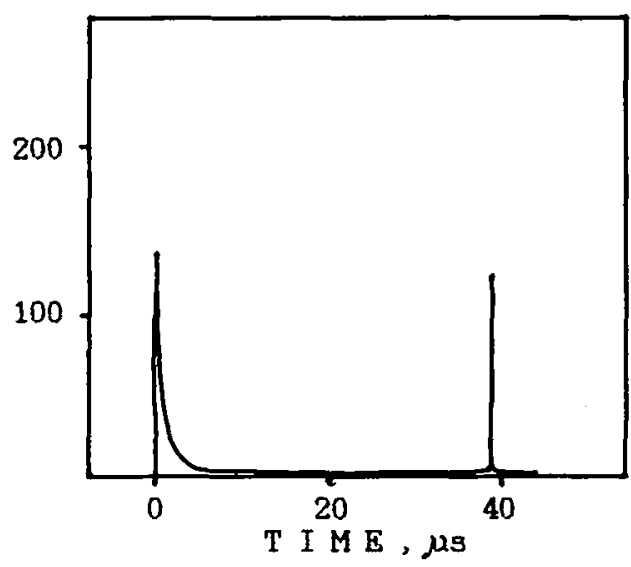

Fig.7. Excitation of $\mathrm{Na}$ fluorescence (second peak) in the afterglow

of fluorescence signal was achleved at $40 \mu s$ delay of the laser excitation from the moment of the air breakdown.

The Fig. 7 illustrates the case when concentration of $\mathrm{Na}$ atoms in the air is so small that the emission sigmsl is undistinguishable against the background the plasme own glow. At the same time the fluorescence sigmal (the second peak) may be surely recorded that allows to conclude that lower detection limits can be obtained than those in LIBS technique.

\section{CONCLOSIONS}

Laser induced fluorescence in a hollow cathode discharge provides high sensitivity in the case of atomization of metals in aqueous solutions and in powdered samples. Pulsed operation allows to obtain ultralow detection limits, comparable to those reported by laser fluorescence with electrothermal atomization

It is also shown that the laser fluorescence determination of metals in aerosols with the laser spark atanizatilon has advantages in comparision with the emission analysis.

\section{REFHRRWCES}

1) S.Carol1, Prog. Anal. Atom. Spectr. 6, 253 (1983).

/2/ S.Caroli, J. Anal. Atom. Spectr. 2, 661 (1987).

/3/ A.N.Rudnevsky, V.M.Shlshov, D.E.Maximov, Zn. Pricl. Spectrosc. (in Fussian), 46, 481 (1987).

14/ L.J.Radziemaik1, D.A.Cremers, T.R.Loree, Spectrochim. Acta. 38B, 349 (1983).

15/ L.J.Radziemski, T.R.Loree, D.A.Cremers, Anal. Chem. 55, 1246 (1983).

16/ M.A.Bol'shov. In Laser Analytical Spectrochemistry, Ed. V.S.Letolkhov, Chap.2. Adam Hilger, Bristol (1986).

I/ B.W.Smith, N.Omenetto, J.D.Winefordner, Spectrohim. Acta, 39B, 1389 (1984).

18/ B.W.Smith, J.B. Womack, N.Omenetto and J.D.Winefordner, Appl. Spectrosc., 43,873 (1989).

19/ A.A.Bol'shakov, N.V.Golovenkov, S.V.Oshemkov, A.A.Petrov, J. Anal. Atam. Spectram., 5, 549 (1990).

/10/ B.W.Smith, M.R.Glick, K.N.Spearg, J.D.Winefordner, Appl. Spectrosc., 43, 376 (1989). 